\title{
Lexicografia monolíngue pedagógica e ensino do vocabulário: interfaces teóricas e práticas
}

DOI: http://dx.doi.org/10.21165/el.v49i1.2474

\section{Renato Rodrigues-Pereira'}

\section{Resumo}

Neste artigo refletimos sobre a importância e o uso de dicionários monolíngues pedagógicos no processo de ensino e de aprendizagem de Espanhol como Língua Estrangeira (E/LE), com foco para o Ensino do Vocabulário (EV). Para tanto, além de orientarmo-nos pelos princípios teóricos e metodológicos da Lexicografia Pedagógica (LEXPED), apoiamo-nos em autores que valorizam o desenvolvimento do conhecimento léxico no estudo de línguas. Ademais, propomos uma atividade com exercícios dirigidos com vistas a demonstrar que léxico, texto e dicionário caminham juntos, como possibilitadores de significados e informações para a realização dos sentidos que desejamos.

Palavras-chave: dicionário; léxico; ensino do vocabulário.

1 Universidade Federal de Mato Grosso do Sul (UFMS), Três Lagoas, Mato Grosso do Sul, Brasil; renato.r.pereira@ufms.br; https://orcid.org/0000-0001-9870-3780 


\section{Lexicografía monolingüe pedagógica y enseñanza de vocabulario: interfaces teóricas y prácticas}

\section{Resumen}

Con este artículo, reflexionamos sobre la importancia y sobre el uso de los diccionarios monolingües pedagógicos en el proceso de enseñanza y de aprendizaje de Español como Lengua Extranjera (E/LE), con foco a la Enseñanza de Vocabulario (EV). Para ello, además de los aportes teóricos y metodológicos de la Lexicografía Pedagógica (LEXPED), buscamos apoyo en autores que valoran el desarrollo del conocimiento léxico en el estudio de lenguas. Además, proponemos una actividad con ejercicios dirigidos cuyo objetivo es demostrar que léxico, texto y diccionario caminan juntos, como posibilitadores de significados e informaciones para la realización de los sentidos que deseamos.

Palabras-clave: diccionario; léxico; enseñanza de vocabulario.

\section{Introdução}

Os estudos lexicográficos de natureza pedagógica se voltam ora para a elaboração de dicionários destinados a estudantes, em que parâmetros são propostos e/ou aplicados, ora ao uso dos diferentes dicionários pedagógicos existentes em contextos escolares. No processo de ensino/aprendizagem de uma língua estrangeira, em especial, ter acesso a bons materiais didáticos ${ }^{2}$ resulta importante para que as variadas atividades de comunicação sejam realizadas de forma mais efetiva.

Os dicionários pedagógicos, neste contexto, podem cumprir um papel de considerável importância na didática de línguas, posto que as informações disponíveis em cada parte de suas organizações estruturais geralmente são registradas com vistas a facilitar o processo de pesquisa do potencial consulente e consequente aprendizagem da informação desejada.

Neste artigo, tratamos da importância e do uso de dicionários monolíngues pedagógicos no processo de ensino e de aprendizagem de Espanhol como Língua Estrangeira (E/ $\mathrm{LE})$, com foco para o Ensino do Vocabulário (EV). Para tanto, objetivamos i) discorrer a respeito da Lexicografia Pedagógica ${ }^{3}$ (LEXPED) e do EV, com vistas a evidenciar as

2 Compreende-se por materiais didáticos os distintos recursos impressos, audiovisuais, multimídia, etc., que são utilizados no processo de ensino/aprendizagem de uma língua. Para uma melhor compreensão a respeito dos diversos tipos existentes, sugerimos conferir Eres Fernández (2010, p. 73) e o Diccionario de Términos Clave de E/LE, disponível em: https://cvc.cervantes.es/ensenanza/ biblioteca_ele/diccio_ele/default.htm. Acesso em: 20 ago. 2019.

3 Lexicografia Pedagógica é um termo por vezes substituído por Lexicografia Didática ou vice-versa. 
interfaces existentes entre essas duas áreas; ii) dissertar sobre o dicionário pedagógico monolíngue em suas diferentes funções e características, como forma de expor algumas considerações relacionadas à importância e ao uso do dicionário monolíngue pedagógico destinado a estudantes em processo de aprendizagem de uma língua, mais especificamente em situações de aprendizagem de E/LE; iii) apresentar uma atividade dirigida ${ }^{4}$ elaborada a partir de necessidades comunicativas do estudante brasileiro de espanhol que se encontra em níveis intermediários (B1 e B2) ou avançados (C1 e C2) de aprendizagem da língua ${ }^{5}$. Para a atividade, elaboramos exercícios com foco no ensino de unidades léxicas ${ }^{6}$ em espanhol desconhecidas pelo estudante no momento da realização da tarefa. Desse modo, almejamos possibilitar ao aluno o entendimento do dicionário monolíngue como um importante material didático de consulta para quando esteja fazendo atividades de leitura e de expressão oral ou escrita; e iv) enfatizar o potencial didático dos dicionários pedagógicos no ensino de línguas.

Tendo em vista nossos objetivos, orientamo-nos pelos princípios teóricos e metodológicos da LEXPED e pelas contribuições de um campo que muito tem evoluído nas últimas décadas: o Ensino do Vocabulário (EV).

\section{Interfaces entre a Lexicografia Pedagógica e o Ensino do Vocabulário}

A LEXPED é uma área da Lexicografia Geral que se ocupa de estudos relacionados aos dicionários pedagógicos dirigidos aos aprendizes de língua materna ou estrangeira. Nesta seara, a área possibilita-nos reflexões tanto a respeito da elaboração de dicionários, como sobre o uso desses dicionários em contextos de ensino e de aprendizagem. Neste contexto, percebe-se que, se os dicionários são pensados e elaborados no contexto dos estudos teóricos e práticos da LEXPED, tanto os estudantes como os professores podem desfrutar de instrumentos pedagógicos que muito contribuem para o ensino de uma língua.

A literatura da área leva-nos a perceber que o predicativo didático/a parece ganhar mais espaço em contextos hispânicos em relação ao pedagógico/a. Como no Brasil temos percebido uma certa preferência por Lexicografia Pedagógica, utilizamos este termo em nossas reflexões.

4 Entendamos por atividade dirigida os exercícios cujas orientações possibilitam o estudante a seguir, sequencialmente, instruções de como fazer cada tarefa, de forma que cada etapa completa a anterior em termos de aprendizagem dos conteúdos em questão e, ainda, induz o aprendiz ao uso de dicionário. A atividade apresentada neste texto, em sua primeira versão, foi objeto de reflexão em comunicação ministrada por Pereira (2014).

5 Em relação aos níveis de aprendizagem de um estudante de língua estrangeira, sugerimos a leitura do MCER (2002), em seu capítulo 3.

6 No âmbito das Ciências do Léxico, o termo unidades léxicas costuma ser empregado para referirse a um, dois ou mais significantes que juntos possuem uma unidade de sentido. A esse respeito, sugerimos conferir Morante Vallejo (2005) e Biderman (2005). 
Welker (2008), ao discorrer sobre os campos de atuação da LEXPED, divide a área em duas vertentes: i) LEXPED teórica - responsável por todo tipo de estudo que se relaciona a dicionários pedagógicos; e ii) LEXPED prática - que se ocupa da produção desses dicionários. Para o estudioso, tais obras diferenciam-se dos dicionários comuns pela preocupação com o aprendiz de línguas ao considerar suas necessidades e habilidades.

Krieger (2011, p. 106), por seu turno, ressalta dois princípios essenciais no contexto da LEXPED, quais sejam: i) busca de adequação do dicionário; ii) uso produtivo para os diferentes projetos de ensino/aprendizagem de línguas. A pesquisadora demonstra-nos ainda que, aos dois itens, deve ser agregada

[...] a compreensão de que o dicionário é um texto, com regras próprias de organização, que sistematiza inúmeras informações de caráter linguístico, cultural e pragmático. Daí resulta seu exponencial papel pedagógico, bem como o princípio de que, assim como há livros didáticos adequados aos diferentes níveis de ensino, de igual modo, deve-se proceder à escolha do dicionário adequado às necessidades de aprendizagem dos alunos. (KRIEGER, 2011, p. 106).

Consideremos que, para que o uso produtivo mencionado pela autora ocorra a contento, é necessário que professor, aluno e materiais didáticos estejam em sincronia. Quer dizer, importa que todas as pessoas envolvidas no processo de ensino e de aprendizagem sejam conhecedoras das distintas e complementares tipologias de dicionários, bem como das várias informações linguísticas e extralinguísticas que essas obras nos oferecem.

Neste cenário, enfatizamos a necessidade de conhecer uma obra lexicográfica em todas as suas possibilidades de informação. Sobre o assunto, Krieger (2007) e Nadin (2013) destacam que o potencial didático do dicionário nem sempre costuma ser explorado em todas as suas possibilidades em sala de aula, pois na maioria dos contextos de ensino os professores ainda desconhecem as características estruturais e funcionais das obras lexicográficas.

Entende-se, dessa forma, que, se pesquisas relacionadas à formação de professores no âmbito da LEXPED, assim como propostas de materiais didáticos que contenham atividades dirigidas que induzam o aluno a utilizar o dicionário ocorram de forma satisfatória, possivelmente haverá uma evolução em relação ao uso produtivo dos distintos repertórios lexicográficos existentes e a serem ainda elaborados por meio do desenvolvimento de projetos que visam à elaboração de dicionários pedagógicos.

No tocante ao EV, a atenção pedagógica se volta especialmente ao ensino e à aprendizagem das funções e significados das unidades léxicas, posto que o léxico de uma língua é o que mais representa os anseios, as intenções designativas de natureza geral, os aspectos sociais, linguísticos e históricos de um povo. 
Em razão do caráter emblemático que o léxico possui, desde muito pequenos, quando começamos a pronunciar os primeiros sons de palavras, "utilizamos o léxico da língua para falar, ler ou escrever, pois ele constitui um dos pilares fundamentais da comunicação verbal [...]"7 (ALVAR EZQUERRA, 2003, p. 7, tradução e destaque nossos).

Isto posto, ressaltamos que o EV se torna ainda mais importante em contextos de ensino/ aprendizagem à medida que as pessoas envolvidas no processo começam a valorizar as lexias como possuidoras de sentidos e funções que possibilitam a realização de sentidos diversos nos diferentes contextos discursivos que nos encontramos e em conformidade com nossas intenções comunicativas.

Em Higueras (2000), encontramos que os alunos sempre manifestam que às vezes não podem se expressar porque não conhecem o léxico adequado. Por mais que a paráfrase seja uma estratégia importante e muito utilizada pelos alunos, por vezes as produções se prolongam de forma desnecessária, produzindo erros de compreensão, justamente pelo desconhecimento do léxico.

MoranteVallejo (2005, p. 8), porsuavez, discorre sobreo desenvolvimento do conhecimento léxico em segundas línguas e nos apresenta que "tanto os aprendizes quanto os falantes nativos percebem os erros léxicos como obstáculos para a comunicação. Ampliar o vocabulário é uma necessidade inclusive para os aprendizes avançados"8.

Nossa experiência enquanto professor de línguas, português como língua materna e espanhol como língua estrangeira, permite-nos corroborar a assertiva dos autores supracitados, uma vez que, em muitas situações de ensino, nossos alunos não conseguem expressar o que desejam por falta de conhecimento de distintos aspectos do léxico da língua em estudo. A esse respeito, buscamos as palavras de Wilkins (1972, p. 111), para quem "sem gramática pode-se comunicar muito pouco, sem vocabulário não se pode comunicar nada"9. Não o fazemos como forma de desmerecer o ensino da gramática da língua, mas com o objetivo de enfatizar a necessidade de um olhar mais atento para as unidades léxicas enquanto possuidoras e possibilitadoras de significados e que, sem o conhecimento delas, nem mesmo questões de gramática podem ser estudadas.

7 No original: "del léxico, echamos mano en cuanto empezamos a hablar, leer o escribir, pues el léxico constituye uno de los pilares fundamentales de la comunicación verbal [...]".

8 No original: "tanto los aprendices como los hablantes nativos perciben los errores léxicos como obstáculos para la comunicación. Ampliar el vocabulario es una necesidad incluso para los aprendices avanzados".

9 No original: "sin gramática se puede comunicar muy poco, sin vocabulario no se puede comunicar nada". 
Neste âmbito, salientamos ainda o posicionamento de Antunes (2007, p. 42) para quem o léxico é mais que uma lista de palavras à disposição dos falantes, "é um depositório de recortes com que cada comunidade vê o mundo, as coisas que o circundam ou o sentido de tudo". Para a autora, é nos textos que elaboramos que o léxico recobre distintas funções e que, como unidades de sentido, as palavras constituem as peças com que se tece a rede de significados do texto, uma vez que são elas que vão materializando e mediando as intenções do nosso discurso.

Pelo exposto, atentemos que o léxico é objeto de estudo e descrição tanto da LEXPED quanto do EV, porém, com funções diferentes. Naquela, estuda-se e descreve-se o léxico numa perspectiva pedagógica com vistas a registrá-lo em repertórios lexicográficos destinados a aprendizes de línguas para que os estudantes tenham materiais didáticos organizados de maneira mais coerente com as necessidades em questão, assim como sirvam de apoio nas atividades de aprendizagem de línguas. No EV, valoriza-se a aprendizagem do léxico em seus múltiplos sentidos e funções, de forma que o aluno consiga estabelecer diálogos escritos e falados de maneira competente e de acordo com o contexto em que se encontre.

Ressaltamos, portanto, a afırmação de Garcia (1977), que enfatiza que se dispomos de palavras suficientes e adequadas à expressão do pensamento de maneira clara, fiel e precisa, estamos em melhores condições de assimilar conceitos, de refletir, de escolher, de julgar, em relação a outros cujo léxico seja insuficiente ou impreciso para a atividade de comunicação.

Os dicionários enquanto materiais didáticos, em especial, ocupam um importante papel no ensino de línguas, principalmente se os utilizamos em todas as suas possibilidades e tipologias. Entre os que existem no mundo acadêmico, a exemplo dos bilíngues, dos monolíngues, dos especiais de língua (de sinônimos, de verbos, de homônimos, etc.), dos especializados, nos debruçaremos, a seguir, nas características, nas funções e importância dos dicionários monolíngues pedagógicos, com especial atenção aos destinados a aprendizes de E/LE ${ }^{10}$.

10 Como exemplos de dicionários monolíngues para aprendizes de E/LE utilizados no Brasil, mencionamos três que muito utilizamos em nossas aulas, quais sejam: o Diccionario de español para extranjeros - con el español que se habla hoy en España y en América Latina, de González (2005), - Diccionario Salamanca - español para extranjeros, de Gutiérrez Cuadrado e Pascual Rodríguez (2006) e o Diccionario básico de la lengua española, de Sánchez (2003). 


\section{Características, funções e importância do dicionário monolíngue de aprendizagem}

Os dicionários monolíngues de aprendizagem (DMA), geralmente, oferecem ao consulente informações gramaticais, sociolinguísticas, defınições, exemplos de uso e informações enciclopédicas, por exemplo, que muito contribuem no processo de aprendizagem de uma língua, ao passo que tais informações possibilitam ao estudante manter contato com discursos oriundos de variados contextos, assim como elaborar seus próprios enunciados.

Conforme Hernández (1996), os DMA direcionados a estudantes estrangeiros devem ser diferentes dos dicionários monolíngues destinados a nativos de uma língua, posto que as necessidades também são distintas. Para Hernández, os estudantes nativos usam o dicionário majoritariamente para comprovar a ortografia e para a compreensão. Já os estudantes estrangeiros, por sua vez, necessitam do dicionário tanto para a compreensão como para a produção.

Por seu turno, Martín García (1999) sobreleva que os dicionários dessa tipologia precisam incluir exemplos que possibilitem determinar o uso da palavra e esclarecer o significado. Outrossim, as definições devem ser mais elucidativas do que nos dicionários monolíngues direcionados a falantes nativos, devendo conter inclusive informação elementar que pode resultar supérflua em muitos casos para um falante nativo.

Percebe-se que os DMA necessitam, portanto, de um olhar mais didático por parte de lexicógrafos de orientação pedagógica no processo de elaboração desses repertórios, visto que eles podem cumprir diferentes funções no contexto de ensino/aprendizagem de uma língua estrangeira.

Hernández (2000), assim como Martín García (1999), ressalta a pertinência de se oferecer aos alunos repertórios lexicográficos com definições que sejam autênticas explicações, o que é perfeitamente possível com um dicionário monolíngue pedagógico que, por sua natureza, haverá de ser distinto dos que se destinam aos estudantes nativos. De acordo com o autor, seriam estes os dicionários monolíngues para usuários estrangeiros, denominados na lexicografia anglo saxã de learner's dictionaries e que, em contexto espanhol, têm sido designados de diccionarios de aprendizaje.

Como se pode observar, os DMA podem cumprir importantes funções devido às características que possuem, como demonstraremos na sequência deste artigo. Nesse contexto, importa destacar que, em situações de ensino de línguas estrangeiras, em especial, a depender do nível de conhecimento da língua, os estudantes precisam ter 
acesso a tipos de dicionários de acordo com o grau de competência comunicativa ${ }^{11} \mathrm{em}$ que se encontram. Por isso, faz-se necessário que discorramos também a respeito dos dicionários bilíngues, pois, em algumas situações de produção e recepção de textos, esta tipologia resulta indispensável.

Entretanto, salientamos que escolher um repertório lexicográfico que consiga oferecer "tudo" que um potencial consulente necessita é quase impossível. Primeiro, porque o que precisa um usuário não necessariamente necessita o outro, pois distintos são os aspectos linguísticos e extralinguísticos conhecidos ou não pelo estudante. E isso determina o grau de conhecimento sobre a língua e seu uso. Segundo, porque o dicionário, tanto no suporte livro impresso, ou até mesmo no suporte eletrônico, nunca conseguirá registrar todo o acervo lexical de uma língua, assim como os aspectos morfo-funcionais e pragmáticos de um idioma.

O fato é que, em toda atividade de comunicação, o usuário de uma língua está sempre lidando com habilidades de recepção e de produção, sejam orais ou escritas. Neste contexto, o dicionário, tanto o bilíngue quanto o monolíngue, pode ser utilizado em atividades de codificação/produção (expressão oral ou escrita) e decodificação/ compreensão (leitura e compreensão oral).

Sobre o assunto, Martínez Marín (1990) já destacava que uma das novidades fundamentais apresentadas pela lexicografia aplicada aos dicionários destinados ao ensino/aprendizagem de línguas estrangeiras é o atendimento ao aspecto da produção, ou seja, a codificação de enunciados e textos de variados tipos, segundo o nível dos dicionários que, por sua vez, depende da categoria de destinatários da obra, assim como o da compreensão, ou decodificação. O autor acrescenta ainda que, desta forma, o dicionário passa a ser pensado, no seu processo de elaboração, para ser útil tanto ao conhecimento ativo da língua como ao passivo. Fato este com consequências importantes nas informações a serem registradas nos verbetes do dicionário.

11 Almeida Filho (2013), tendo como base as contribuições teóricas de Chomsky (1965), Hymes (1979), Canale e Swain (1980), Canale (1983), Tarone (1980) e Widdowson (1989), entre outros, representa a competência comunicativa como o resultado de competências que o participante da interação, a depender do grau de acesso aos conhecimentos disponíveis, tem ou adquire, a saber: competência linguística que demanda conhecimentos sobre o código em questão; competência sociocultural, em que os conhecimentos extralinguísticos e estéticos são evidenciados em situações de interação; competência meta, quando os conhecimentos metalinguísticos e metacomunicativos são ressaltados, como forma de possibilitar uma reflexão sobre seus valores funcionais e pragmáticos; competência estratégica, referente a conhecimentos e mecanismos de sobrevivência na interação, ou seja, a capacidade de produzir e compreender textos adequados à produção de efeitos de sentido desejados em situações específicas e concretas de interação comunicativa. 
Hernández (1998, p. 70, tradução nossa ${ }^{2}$ ), por seu turno, ao refletir sobre as funções dos dicionários monolíngues e bilíngues, classifica o monolíngue somente como de função decodificadora, a saber:

[...] os dicionários monolíngues cumprem com uma função meramente decodificadora de mensagens elaboradas na própria língua do usuário, e os bilíngues, ademais da função decodificadora (traduzir textos de uma língua desconhecida em relação à materna) uma função codificadora (elaboração de mensagens em uma segunda língua a partir da primeira. Aos dicionários monolíngues, pois, somente thes são exigidos o cumprimento de uma função decodificadora e aos bilíngues a capacidade de decodificar e codificar textos em uma segunda língua, pelo menos alguns conhecimentos elementares.

Sánchez López (2013), por sua vez, salienta a função codificadora do dicionário monolíngue em processos de tradução, quando ocorre a elaboração de mensagens em uma segunda língua a partir da primeira. A pesquisadora enfatiza ainda que esta é uma função que geralmente é atribuída ao monolíngue, como esclarece Hernández (1998), e não ao bilíngue.

Ainda conforme Sánchez López (2013, p. 24), a função codificadora "é uma qualidade reconhecida aos dicionários didáticos/pedagógicos"13 em geral. Assim como Martínez Marín (1990) e Sánchez López (2013), também entendemos o DMA como de função codificadora e não apenas decodificadora.

Em face das reflexões expostas nos parágrafos anteriores a respeito das características dos DMA, em especial, e igualmente sobre as funções dos monolíngues e dos bilíngues, passamos a discorrer, na sequência, sobre a importância dos dicionários monolíngues, sobretudo quando os alunos estão em níveis intermediários e avançados de aprendizagem de uma língua estrangeira.

Pelas informações disponíveis no MCER (2002) a respeito dos níveis comuns de referência numa escala global, entende-se que, ao estudante que se encontra em níveis básicos de

12 No original: "[...] los diccionarios monolingües cumplen con una función meramente descodificadora de mensajes elaborados en la propia lengua del usuario, y los bilingües, además de la función descodificadora (traducir textos de una lengua desconocida a la materna) una función codificadora (elaboración de mensajes en una segunda lengua a partir de la primera. A los diccionarios monolingües, pues, sólo se les exige el cumplimiento de una función descodificadora y a los bilingües la capacidad de descodificar y codificar textos en una segunda lengua de la que se poseen, al menos, unos conocimientos elementares".

13 No original: "es una cualidad que se le reconoce a los diccionarios didácticos". 
aprendizagem (A1 e A2), por exemplo, pelo pouco conhecimento que ainda possui sobre a língua, recomenda-se a utilização de um dicionário bilíngue. Desse modo, pelo processo de decodificação, o aluno deve compreender uma mensagem em uma língua que não é sua língua materna em situações de leitura e, ainda, pelo processo de codificação, pode o dicionário bilíngue possibilitar a elaboração de mensagens, ainda que menos elaboradas, em uma segunda língua ou estrangeira, a partir da primeira.

Em níveis intermediários e avançados (B1, B2 e C1, C2), além do dicionário bilíngue em situações discursivas que o estudante não conheça de fato nenhuma palavra que supra sua necessidade de produção na língua estrangeira, por exemplo, o dicionário monolíngue resulta muito importante e funcional. O estudante de E/LE, então possuidor de habilidades e competências múltiplas que lhe permitem não só ler e compreender um texto com mais fluência, como também produzir enunciados com maior competência, terá, no dicionário pedagógico, informações diversas, como as explicitadas alhures, que Ihe conferem a função codificadora e decodificadora de mensagens.

Nessa esteira, cumpre lembrar as palavras de Castillo Carballo e García Platero (2003, p. 344, tradução nossa ${ }^{14}$ ) que, ao explicarem sobre quando usar o dicionário bilíngue e o monolíngue, esclarecem ser "inegável que nos primeiros anos de aprendizagem os repertórios bilíngues são um instrumento eficaz. Certamente, o usuário encontrará com facilidade as equivalências necessárias, uma vez que seu conhecimento sobre a língua meta não é elevado [...]". Já referindo ao dicionário monolíngue, os autores explicam que a situação se modifica; à medida que os estudantes adquirem maior conhecimento cultural e linguístico da nova realidade que estão vivenciando, suas necessidades aumentam consideravelmente.

Outrossim, buscamos também Prago Aragonés (2004, p. 157-158, tradução nossa ${ }^{15}$ ), que nos esclarece que os dicionários "[...] não são só obras linguísticas [...], são também instrumentos culturais que incluem informação sobre o mundo e a cultura da comunidade que fala essa língua". A autora ressalta também que as informações culturais e enciclopédicas no dicionário geralmente são apresentadas em algumas ocasiões na definição, mas, principalmente, por meio dos exemplos, em que são mostrados de forma contextualizada os modelos de uso da língua, assim como as marcas pragmáticas de uso, com a fraseologia, as ilustrações, etc. Todos estes aspectos qualificam o DMA como um dicionário também de função codificadora, posto que as informações disponíveis nesta tipologia de dicionários contribuem para o desenvolvimento da competência comunicativa

14 No original: "innegable que en los primeros años de aprendizaje los repertorios bilingües son un instrumento eficaz. Ciertamente, el usuario encontrará con facilidad las equivalencias necesarias, dado que su conocimiento de la lengua meta no es elevado [...]".

15 No original: "[...] no son sólo obras lingüísticas [...], sino que también son instrumentos culturales que incluyen información sobre el mundo y la cultura de la comunidad que habla esa lengua". 
dos alunos nas variadas práticas de ensino existentes, permitindo-lhes realizar distintas atividades em sala de aula e fora dela, o que Ihes possibilita, consequentemente, a ampliação dos conhecimentos que já possuem enquanto estudantes.

\section{0 dicionário monolíngue pedagógico nas aulas de E/LE: proposta de atividade}

Os exercícios apresentados na sequência deste artigo foram organizados com o objetivo de possibilitar o desenvolvimento do conhecimento léxico do aprendiz de E/LE, mais especificamente do estudante da língua que se encontra em níveis intermediários (B1 e B2) ou avançados (C1 e C2) de aprendizagem, como já explicamos em seções anteriores.

Resulta importante lembrar, neste contexto, que até os anos oitenta do século passado, quando tínhamos um ensino estritamente de natureza formalista dos estudos estruturalistas, o ensino de vocabulário não passava de listas de palavras com objetivos de memorização e/ou tradução ${ }^{16}$. Elas não recebiam o tratamento merecido, ficando, pois, em segundo plano em relação ao ensino da gramática.

Dos anos oitenta à atualidade, graças aos estudos lexicais com fins de descrição e ensino, assim como do advento de correntes de estudos como a Linguística Textual, a Análise do Discurso, a Linguística Aplicada, a Sociolinguística e a Pragmática, por exemplo, o ensino em geral passa por transformações positivas. O léxico, neste cenário, começa a ser entendido como possuidor e possibilitador de sentidos.

Desse modo, o ensino do léxico, já numa perspectiva funcional e pragmática, permite que os estudantes sejam colocados em situações de produção e compreensão de discursos autênticos em conformidade com a intenção ou necessidade comunicativa em questão. Vale ressaltar que aqui nos referimos aos princípios oriundos da abordagem comunicativa de ensino/aprendizagem de línguas.

Retomando a apresentação dos exercícios, destacamos que eles foram elaborados a partir de práticas de leitura, de compreensão, de pesquisa e de produção de textos escritos e orais. Ao utilizarmos o vocativo ¡Fíjate!, iniciamos a atividade explicando, numa linguagem adequada ao estudante, o valor da palavra em suas múltiplas funções, exaltando sua função codificadora e decodificadora, para, na sequência, apresentar o exercício, a saber:

16 Para um conhecimento mais amplo sobre como era visto o ensino do léxico desde os contextos estruturalistas aos contemporâneos, sugerimos a leitura de Morante Vallejo (2005). 


\section{Actividad}

¡Fíjate!

La palabra es la materialización del pensamiento ${ }^{17}$.

Por ello, cuanto más la conocemos en sus múltiples valores, podemos comprender y significar los distintos discursos existentes. Ella se nos permite el libre arbitrio de ir y venir a lugares nunca antes posibles. Pero para ello, necesitamos conocerla, usarla, testarla, al punto de permitir que sus efectos de sentido se realicen, o sean realizados.

Sigue atentamente cada orientación dictada en los ejercicios en la secuencia. No obstante, para que consigas realizar la tarea con más competencia, ten entre manos por lo menos un diccionario monolingüe.

Nota: se puede escribir las respuestas en el cuaderno.

1. Lee el texto abajo y subraya las palabras que no conozcas.

El desierto de Atacama $^{18}$ Soy fotógrafa. Mi primera máquina fotográfica la recibí de regalo de mi padre cuando tenía nueve años. Desde entonces he fotografiado personas, animales, cosas, paisajes, tragedias, alegrías, en fin, he fotografiado la vida.

Creo que la mayor satisfacción que la fotografía profesional me proporciona son los viajes. Las revistas para las que trabajo necesitan material de diversas partes del mundo y a veces me ha tocado a mí la gran suerte de proveer ese material. Como ahora, que viajo a Chile, país que no conozco, para realizar fotos del desierto de Atacama. Poco o nada sé de este desierto, y curiosa, busqué todas las informaciones posibles sobre este apartado lugar en el norte del país. Yo ya sabía que era el desierto más árido del mundo, con zonas que jamás reciben lluvias, pero fue una sorpresa saber las grandes variaciones de temperatura que existen entre el día y la noche, diferencias que alcanzan hasta los $35^{\circ}$. Como el desierto queda entre dos cordilleras: la de la Costa y la de los Andes, su extrema aridez se debe a las grandes alturas de la cordillera de los Andes, con cumbres que superan los seis mil metros, que impiden el paso de las nubosidades que surgen de la zona amazónica. Un leve rocío nocturno no es suficiente para mojar la árida tierra de evidente origen volcánico.

17 "A palavra é a materialização do pensamento" (PEREIRA, 2018, p. 194).

180 texto utilizado nesta atividade é exemplificativo, podendo o leitor substituí-lo a depender de suas necessidades pedagógicas. 
La primera visión que tuve del desierto fue desde el avión a la llegada a Calama. El brillo de unas cúpulas me llamó la atención. Era el observatorio astronómico de Paranal, el más grande del hemisferio sur. Tiene cuatro gigantescos telescopios de 200 toneladas cada uno que flotan en ocho milímetros de aceite, con tres enormes espejos que más parecen discos compactos de inconmensurable tamaño. Científicos de ocho naciones europeas trabajan intensamente para descubrir los misterios del cosmos. Cada país aportó 500 millones de dólares para la construcción y puesta en operaciones.

Mi segunda visión, esta vez ya en tierra, no fue menos fantástica: el Valle de la Luna, a mitad de camino entre Calama y el poblado de San Pedro de Atacama. Este valle semeja el fondo de un cráter. Es un lugar solitario y muy seco y realmente sobrecoge a quien lo ve por primera vez.

El Valle de la Luna representa la expresión más rigurosa del desierto, ya que no existen aquí evidencias de vida vegetal ni orgánica. Sus colores, texturas y formas más parecen ser obras de un imaginario escultor que producto de la naturaleza. Sus monumentos naturales son formaciones de piedra y sal modeladas por el inclemente sol y el intenso frío nocturno. Viento, sol y frío actúan como verdaderos cinceles erosionadores, entregando visiones de ensueño e irrealidad. La similitud con la superficie lunar es tanta, que el Programa Espacial de los EE.UU., NASA, ha realizado expediciones de astronautas a este valle, a fin de acostumbrarlos al panorama de soledad que les espera en sus viajes. Mientras elegía los mejores ángulos para mis fotografías me sentía protagonista de una película de ciencia ficción.

Mi próxima parada fue el pueblo de San Pedro de Atacama. En este pueblo no hay tiendas, bares, hoteles ni tráfico. La luz pública se apaga a las diez de la noche y solo se ve el brillo de las estrellas en la inmensidad del cielo. La vida apacible de los pobladores, no más de mil, se ve constantemente interrumpida por la presencia de fotógrafos de todas las nacionalidades. 
El chofer del "jeep" que me llevó me hizo un recuento de los principales acontecimientos del pueblo. El 29 de junio, día de San Pedro, los pobladores se visten de gala y hacen procesión llevando la imagen del patrono San Pedro por las estrechas callecitas, mientras grupos disfrazados con ropas coloridas y máscaras enormes cantan y bailan al son de instrumentos folclóricos de viento tales como la zampoña, la quena, la flauta e instrumentos de cuerdas como el charango, de seis cuerdas dobles, cuya caja de resonancia está hecha con la caparazón de un animalito de la precordillera, el quirquincho o tatú. La riqueza del folclor musical ha llamado mucho la atención de los estudiosos que han participado de esta fiesta, por la sonoridad, el ritmo y la cadencia marcada con los instrumentos de percusión: el bombo, el tambor y la caja.

Mi repertorio de fotografías crecía tanto como mi experiencia en ese desierto árido, agresivo y encantador a la vez.

El punto final de mi expedición fue El Tatio. Quien va al desierto no puede perder este espectáculo soberbio de la naturaleza. Salimos de madrugada, más o menos a las cuatro de la mañana rumbo a El Tatio, a 4.200 m sobre el nivel del mar. Al llegar, el viajero descubre trece geyseres - fuentes geotérmicas - que lanzan chorros de vapor a ocho o nueve metros de altura, con temperatura que alcanza los $85^{\circ} \mathrm{C}$. Fotografié la escena varias veces, tratando de seguir, un poco inútilmente, las variaciones de altura e intensidad de los chorros de vapor.

Al bajar al llano pude captar con mi máquina grupos de llamas y alpacas que buscaban la escasa hierba que crece en pequeños oasis.

Ya entregué las fotos a la revista. El viaje de una semana al desierto me dejó un poco cansada, pero feliz. Mi próximo destino es una exuberante región: la selva amazónica en Brasil.

(LIMA, 1999, p. 157-159)

2. Lee el texto otra vez e intenta comprender las palabras que has subrayado. No te olvides de registrar tus comprensiones.

3. Escribe las palabras que no hayas comprendido en la columna de la izquierda del cuadro abajo. En seguida, busca en un diccionario monolingüe su(s) significado(s) y escríbelo(s) en la columna de la derecha. 


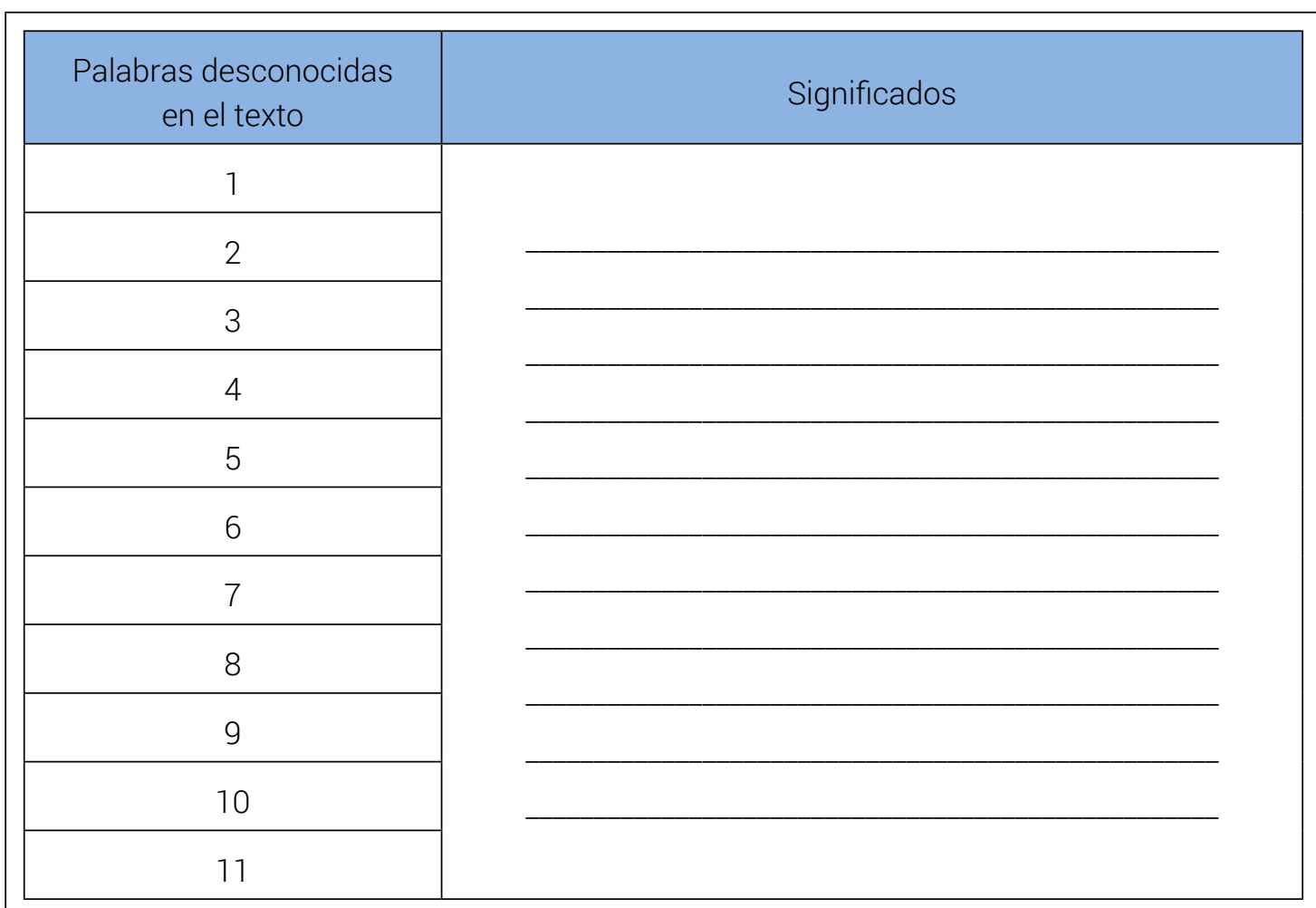

4. Ahora, como ya conoces los significados de las palabras, escribe un texto en que utilices, por lo menos, la mitad de las palabras escritas y definidas en el ejercicio anterior.

5. Por fin, en parejas, discutan sobre los dos textos, "El desierto de Atacama" y el que escribiste en el ejercicio anterior. En la secuencia, tendrás dos opciones para hacer con los otros compañeros de clase: i) hacer un resumen hablado del texto leído y; ii) hablar respecto al texto producido en el ejercicio 4, explicando las diferencias y las semejanzas en relación al asunto tratado en esta actividad.

Com esta atividade dirigida, passível de ser adaptada a diferentes textos e línguas, objetivamos oferecer a oportunidade de leitura e reflexão sobre unidades léxicas de forma direta, posto que o estudante de níveis intermediários e avançados já consegue realizar interpretações que exigem uma competência decodificadora e codificadora mais desenvolvida. Desse modo, esperamos que o estudante adquira um olhar mais atento ao léxico da língua, com foco para seus usos e funções pragmáticas, assim como entenda o dicionário como importante instrumento de consulta em atividades de produção e compreensão. 


\section{Considerações finais}

Com as reflexões realizadas neste texto, sobrelevamos a importância do dicionário como importante material didático a ser utilizado de forma efetiva em situações de ensino/ aprendizagem de línguas em que o léxico não seja tratado de forma secundária, e sim com o valor que lhe é mister.

Em conformidade com os objetivos estabelecidos para este texto, discorremos sobre a Lexicografia Pedagógica e o Ensino do Vocabulário em suas interfaces, como forma de demonstrar que, embora ambas áreas tenham o léxico como objeto de estudo e descrição, cada uma o analisa e descreve com objetivos diferentes. Mas que, em todos os casos, possibilitam o conhecimento, o aprendizado, o uso adequado das unidades léxicas da língua.

Em relação ao dicionário pedagógico monolíngue em suas diferente funções e características, apresentamos algumas considerações relacionadas à importância e ao uso do dicionário monolíngue pedagógico, e também do bilíngue, em situações de ensino/ aprendizagem do E/LE, em que os alunos precisam realizar atividades de decodificação e codificação de maneira competente.

Com a atividade dirigida apresentada, esperamos ter oferecido uma proposta funcional que sirva de instrumento para o desenvolvimento do conhecimento léxico dos alunos, assim como suscitar os colegas professores que utilizarem a atividade e suas aulas de E/LE ou adaptarem-na a outras línguas e textos a usarem o dicionário como importante material didático que muito ainda precisa ser explorado em sala de aula.

Com base no exposto, esperamos haver instigado um olhar mais atento ao léxico da língua em contextos de ensino/aprendizagem, assim como enfatizado o potencial didático dos dicionários pedagógicos no ensino de línguas, em especial.

\section{REFERÊNCIAS}

ANTUNES, I. Muito além da gramática: por um ensino de línguas sem pedras no caminho. São Paulo: Parábola Editorial, 2007.

ALVAR EZQUERRA, M. La enseñanza del léxico y el uso del diccionario. Madrid: Arco Libros, S.L., 2003.

ALMEIDA FILHO, J. C. P. Dimensões comunicativas no ensino de línguas. 7. ed. Campinas: Pontes, 2013. 
BIDERMAN, M. T. C. Unidades complexas do léxico. In: RIO-TORTO, G. et al. (org.). Estudos em homenagem ao Professor Doutor Mário Vilela. Porto: Faculdade de Letras da Universidade do Porto, 2005. p. 747-757.

CANALE, M.; SWAIN, M. Theoretical Bases of Communicative Approaches to Second Language Teaching and Testing. Applied Linguistics, v. 1, n. 2, p. 1-47, 1980.

CASTILLO CARBALLO; M. A.; GARCÍA PLATERO, J. M. La lexicografía didáctica. In: MEDINA GUERRA, A. M. (coord.). Lexicografía Española. Barcelona: Ariel, 2003. p. 333-351.

CHOMSKY, N. Aspects of the Theory of Syntax. Cambridge, Mass: The MIT Press, 1965.

Diccionario de Términos Clave de E/LE. In: Centro Virtual Cervantes. Disponível em: https:// cvc.cervantes.es/ensenanza/biblioteca_ele/diccio_ele/default.htm. Acesso em: 20 ago. 2019.

ERES FERNÁNDEZ, G. Entre enfoques y métodos: algunas relaciones (in)coherentes en la enseñanza de español lengua extranjera. In: BARROS, C. S. de; COSTA, E. G. de M. Espanhol: ensino médio. Brasília: Ministério da Educação, Secretaria de Educação Básica, 2010.

GARCIA, O. M. Comunicação em prosa moderna. Rio de Janeiro: Editora da fundação Getúlio Vargas, 1977.

GONZÁLEZ, M. C. Diccionario de español para extranjeros - Con el español que se habla hoy en España y en América Latina. Coordinación y proyecto editorial Concepción. São Paulo: Edições SM, 2005.

GUTIÉRREZ CUADRADO, J.; PASCUAL RODRÍGUEZ, J. A. Diccionario salamanca - español para extranjeros. Santillana Educación: Madrid, 2006.

HERNÁNDEZ, H. El nacimiento de la lexicografía monolingüe española para usuarios extranjeros. In: RUEDA, M.; PRADO, E.; LE MEN, J.; GRANDE, F. J. (org.). Actuales tendencias en la enseñanza del español como lengua extranjera II. Universidad, León, 1996. p. 203-2010.

HERNÁNDEZ, H. La lexicografía didáctica del español: aspectos históricos y críticos. In: FUENTES MORÁN, M. T. (org.). Lexicografías iberorrománicas: problemas, propuestas proyectos. Madrid: Iberorrománica, 1998. p. 49-79. 
HERNÁNDEZ, H. El diccionario en la enseñanza de E. L. E. (Diccionarios de español para extranjeros). In: ASELE. Actas XI (2000).

HIGUERAS, M. Favorecer el aprendizaje del léxico. Boletín de la Asociación para la Enseñanza del Español como Lengua Extranjera, v. 23, p. 13-18, 2000.

HYMES, D. On Communicative Competence (extracts). In: BRUMFIT, C. J.; JOHNSON (org.). The Communicative Approach to Language Teaching. Oxford: Oxford University Press, 1979.

KRIEGER, M. da G. Questões de lexicografia pedagógica. In: XATARA, C.; BEVILACQUA, C. R.; HUMBLÉ, P. R. (org.). Dicionários na teoria e na prática: como e para quem são feitos. São Paulo: Parábola Editorial, 2011.

KRIEGER, M. da G. O dicionário de língua como potencial instrumento didático. In: ISQUERDO, A. N.; ALVES, I. M. (org.). As ciências do léxico: lexicologia, lexicografia e terminologia, volume III. São Paulo: Humanitas, 2007.

MARTÍNEZ MARíN, J. El diccionario y la enseñanza-aprendizaje del español como lengua extranjera. In: Actas del Primer Congreso Nacional de ASELE, Granada, Universidad de Granada, p. 307-315, 1990.

MARTÍN GARCÍA, J. El diccionario en la enseñanza del español. Madrid: Arco Libros, S. L. 1999.

MCER. Marco Común Europeo de Referencia para las lenguas: aprendizaje, enseñanza, evaluación. Madrid: Secretaria General Técnica del MCER y Grupo Anaya, Traducido y adaptado por el Instituto Cervantes, 2002.

MORANTE VALLEJO, R. El desarrollo del conocimiento léxico en segundas lenguas. Madrid: Arco Libros, S.L., 2005.

NADIN, O. L. O uso do dicionário nas aulas de español como língua estrangeira: reflexões teórico-práticas. In: NADIN, O. L.; LUGLI, V. C. P. (org.). Espanhol como língua estrangeira. Campinas: Mercado das Letras, 2013.

PRADO ARAGONÉS, J. El ejemplo lexicográfico como referente cultural en la enseñanza del español como lengua extranjera. In: ARAGONÉS, J. P.; CAMACHO, M. V. G. Diccionario, Léxico y cultura. Huelva: Universidad de Huelva, 2004. 
PEREIRA, R. R. O diccionario pedagógico e a homonímia: em busca de parâmetros didáticos. 2018. Tese (Doutorado em Linguística e Língua Portuguesa) - Faculdade de Ciências e Letras, Universidade Estadual Paulista "Júlio de Mesquita Filho", Araraquara, 2018.

PEREIRA, R. R. El diccionario en el aprendizaje del español como lengua extranjera. In: VII. Coloquio PELSE - II ENPORTU - II EUPELE. Universidad de la República Uruguay, Montevideo, 30 e 31 de maio de 2014.

SÁNCHEZ, A. Diccionario abreviado de uso del español actual. Sociedad General Española de Librería, S. A. Alcobendas-Madrid, 2003.

SÁNCHEZ LÓPEZ, I. Léxico, diccionario y enseñanza/aprendizaje de ELE. ASELE. Colección Monografías (Tesis de Doctorado), 2013.

TARONE, E. Communication Strategies, Foreign Talk and Repair in Interlanguage. Language learning, v. 30/2, 1980.

WELKER, H. A. Lexicografia Pedagógica: definições, história, peculiaridades. In: XATARA, C.; BEVILACQUA, C.; HUMBLÉ, P. Lexicografia Pedagógica: pesquisas e perspectivas. Santa Catarina: NUT, 2008.

WIDDOWSON, H. G. Knowledge of Language and Ability for Use. In: Applied Linguistics, v. 10/2, 1989.

WILKINS, D. Linguistics in Language Teaching. London, Edward Arnold, 1972. 